\title{
Azacytidine induces necrosis of multiple myeloma cells through oxidative stress
}

\author{
Enbing Tian', Haiping Tang ${ }^{2}$, Renhua Xu', Chongdong Liu', Haiteng Deng ${ }^{2 *}$ and Qingtao Wang ${ }^{1 *}$
}

\begin{abstract}
Azacytidine is an inhibitor of DNA methyltransferase and is known to be an anti-leukemic agent to induce cancer cell apoptosis. In the present study, multiple myeloma cells were treated with azacytidine at clinically relevant concentrations to induce necrosis through oxidative stress. Necrotic myeloma cells exhibit unique characteristics, including enrichment of the cell-bound albumin and overexpression of endoplasmic reticulum (ER)- and mitochondrial-specific chaperones, which were not observed in other necrotic cells, including HUH-7, A2780, A549, and Hocla. Proteomic analysis shows that HSP60 is the most abundant up-regulated mitochondrial specific chaperone, and azacytidine-induced overexpression of HSP60 is confirmed by western blot analysis. In contrast, expression levels of cytosolic chaperones such as HSP90 and HSP71 were down-regulated in azacytidine-treated myeloma cells, concomitant with an increase of these chaperones in the cell culture medium, suggesting that mitochondrial chaperones and cytosolic chaperones behave differently in necrotic myeloma cells; ER- and mitochondrial-chaperones being retained, and cytosolic chaperones being released into the cell culture medium through the ruptured cell membrane. Our data suggest that HSP60 is potentially a new target for multiple myeloma chemotherapy.
\end{abstract}

Keywords: Necrosis, Cell-bound albumin, Proteomics, Heat shock proteins, Oxidative stress, Myeloma cells

\section{Background}

Multiple myeloma (MM) is a clonal B-cell disorder in which malignant plasma cells (PC) accumulate in the bone marrow, resulting in lytic bone lesions and excessive amounts of monoclonal proteins. It accounts for $10 \%$ of hematologic malignancies. Although therapeutic interventions have been developed and the overall survival has been improved over the last decade [1], myeloma is still incurable and most multiple myeloma patients who survive initial treatment will develop drug resistance, and eventually relapse. Development of new therapeutic interventions is strikingly needed for increasing patient survival rate. It has been shown that abnormal methylation of tumor suppressor genes is a common event in malignant plasma cell disorders [2-4] and aberrant global methylation patterns also affect the molecular pathogenesis of myeloma [3]. Azacytidine, a ring analog of the naturally occurring pyrimidine nucleoside cytidine, is an inhibitor of DNA methyltransferase.

\footnotetext{
*Correspondence: dht@tsinghua.edu.cn; wqt36@163.com

${ }^{2}$ School of Life Sciences, Tsinghua University, Beijing, China

'Beijing Chaoyang Hospital affiliated Capital Medical University, Beijing, China
}

Following incorporation into DNA, azacytidine is capable of covalently binding to DNA methyltransferase, resulting in hypomethylation and transcriptional reactivation of some silenced genes. This has led to development of azacytidine as a therapeutic anti-cancer agent. Azacytidine has been used to treat patients with myelodysplastic syndrome and acute myeloid leukemia at the dose of 75-100 mg/day [5-7]. In vitro studies have shown that azacytidine alone or in combination with other antitumor agents induces tumor cell apoptosis. It has been reported that azacytidine induced ATR-mediated DNA double-strand break responses, apoptosis, and synergistic cytotoxicity in multiple myeloma cells [8]. It has also been demonstrated that a combination of azacytidine and arsenic trioxide generates a synergistic antitumor activity in myeloma [9]. Moreover, azacytidine has been shown to activate the interleukin- 6 and nuclear factor-kB signaling pathways [10], and to induce overexpression of semenogelin I in myeloma cells [11]. To the best of our knowledge, azacytidine induced necrosis in myeloma cells has not yet been reported.

\section{Biomed Central}

(c) 2013 Tian et al.; licensee BioMed Central Ltd. This is an Open Access article distributed under the terms of the Creative Commons Attribution License (http://creativecommons.org/licenses/by/2.0), which permits unrestricted use, distribution, and reproduction in any medium, provided the original work is properly cited. 
Necrosis is one type of cell death that lacks characteristics of apoptosis and autophagy [12-16]. Over the last several years, the occurrence and course of necrosis was found to be programmed and tightly regulated. Extensive studies show that death ligands (e.g., CD95L, TNF and TNF-related apoptosis-inducing ligand) induce caspaseindependent necrotic-like cell death that relies on the activity of the death domain (DD)-containing kinase RIP1. Although the induction mechanisms of necrosis are becoming increasingly clear, the execution of this process remains somewhat elusive. Necrosis is accompanied by a complex sequence of cellular processes including mitochondrial dysfunction with enhanced generation of reactive oxygen species (ROS) and ATP depletion, proteolysis by calpains and cathepsins, and early plasma membrane rupture. One important consequence of necrosis is the induction of immunogenic responses pursuant to the release of immunogens from necrotic cells [17-20]. Basu and colleagues reported that heat shock proteins (HSPs) including gp96, calreticulin, HSP90 and HSP72 were released into the culture supernatant from necrotic cells in response to freeze thaw, but not from apoptotic cells [21,22]. It was further shown that the released HSPs activated the NF- $\mathrm{kB}$ pathway, stimulated macrophages to secrete cytokines, induced the expression of co-stimulatory molecules, and enhanced antigen presentation in dendritic cells [23-28].

A few studies have been reported on necrosis of myeloma cells. Kigamicin, a compound derived from actinomycetes, induces necrosis in human myeloma cells by inhibition of cyclin D1, p21, p-AKT, and p-ERK [29]. A D-amino acid-containing peptide HYD1 increases the reactive oxygen species production, leading to necrotic cell death in multiple myeloma cells [30]. When cells are treated with azacytidine, not only DNA methyltransferase are inhibited, but ROS generation is also observed [31]. For example, ROS generation is used as an indicator for the synergistic and cytotoxic effects of azacytidine in AML and acute lymphoblastic leukemia cells [32,33]. Within cells, mitochondria are susceptible targets for oxidant stress. ROS can modify mitochondrial lipids, proteins, and DNA. The lack of histones in mtDNA also makes mitochondria more vulnerable to oxidative stress $[34,35]$. Oxidative stress also may lead to modifications and alterations of endoplasmic reticulum (ER) chaperone proteins [36], causing the accumulation of unfolded or misfolded proteins, and decreases in protein synthesis. In the present work, we show that azacytidine-treatment induces necrosis of myeloma cells through oxidative stress, and that necrotic myeloma cells exhibit unique characteristics, including enrichment of cell-bound albumin and overexpression of the ER- and mitochondrial-specific chaperones. Expression of HSP60 has been shown to exhibit the largest increase upon azacytidine treatment and HSP60 is a potential binding partner of cell-bound albumin.

\section{Methods}

\section{Chemicals and reagents}

RPMI1640 medium, phosphate-buffered saline (PBS) and fetal bovine serum were purchased from Wisent (Montreal, QC) and used without further purification. Dithiothreitol (DTT) was purchased from Merck (Whitehouse Station, NJ). Sequencing grade modified trypsin was purchased from Promega (Fitchburg, WI). 5-azacytidine, iodoacetamide (IAA) and RNase A were purchased from Sigma (St Louis, MO). Dimethyl sulfoxide was purchased from Applichem (St Louis, MO). A BCA protein assay kit was purchased from Solarbio (Tongzhou District, Beijing). TMT ${ }^{\circ}$ Mass Tagging Kits and Reagents were purchased from Thermo Scientific (Rockford, IL).

\section{Cell Culture and Sample Preparation}

Human MM cell line U266 was purchased from the Tumor Cell Bank of Chinese Academy of Medical Sciences (Beijing, China), and NCI-H929 and RPMI8226 cells were kindly provided by Dr. Wenming Chen (Beijing Chao-Yang Hospital Affiliated to the Capital University of Medical Science). All three cell lines were cultured in RPMI 1640 (Wisent) containing 10\% or 15\% fetal bovine serum with 100 units $/ \mathrm{mL}$ penicillin and $100 \mu \mathrm{g} / \mathrm{mL}$ streptomycin at $37^{\circ} \mathrm{C}$ in a humidified incubator with $5 \% \mathrm{CO}_{2}$. Prior to treatment, cells were cultured for at least $12 \mathrm{~h}$ to reach exponential growth phase. Cells were treated with azacytidine dissolved in dimethyl sulfoxide and the control cells were treated with the same amount of DMSO for the same time periods. After treatments, cells were washed twice with ice-cold PBS and lysed with RIPA lysis buffer $(25 \mathrm{mmol} / \mathrm{L}$ Tris- $\mathrm{HCl}$ $\mathrm{pH}$ 7.6, $150 \mathrm{mmol} / \mathrm{L} \mathrm{NaCl}, 0.1 \%$ SDS, 1\% NP-40, 1\% sodium deoxycholate, $1 \mathrm{mmol} / \mathrm{L} \mathrm{PMSF}$, and Roche Complete Protease Inhibitor Cocktail) for $30 \mathrm{~min}$ on ice. Cell lysates were clarified by centrifugation at $14,000 \times \mathrm{g}$ for $20 \mathrm{~min}$ at $4^{\circ} \mathrm{C}$. The protein concentration in the supernatant of each sample was determined using a BCA protein assay kit.

\section{Protein Separation by 1D SDS-PAGE and Proteomics Analysis}

Equal amount of proteins from untreated- and azacytidine-treated samples (about $30 \mu \mathrm{g}$ ) were separated by 1D SDS-PAGE, respectively. The gel bands of interest were excised from the gel, reduced with $25 \mathrm{mM}$ of DTT and alkylated with $55 \mathrm{mM}$ iodoacetamide. In gel digestion was then carried out with sequencing grade modified trypsin in $50 \mathrm{mM}$ ammonium bicarbonate at $37^{\circ} \mathrm{C}$ overnight. Peptides were extracted twice with $0.1 \%$ trifluoroacetic acid in 50\% acetonitrile aqueous solution 
for $30 \mathrm{~min}$. The extracts were then centrifuged in a speedvac to reduce the volume. To analyze the proteins in the cell culture medium of untreated and azacytidinetreated U266 cells, cells were cultured in RPMI 1640 medium containing $0.5 \%$ fetal bovine serum for $48 \mathrm{~h}$ and the culture mediums were collected. Proteins from the same volume of cell culture mediums were separated by $1 \mathrm{D}$ SDS-PAGE, and the gel bands were excised and digested with trypsin. For protein quantitation, peptides from different samples were labeled with TMT reagents purchased from Thermo-Pierce Biotechnology (Rockford, IL) according to the manufacturer's instructions. Briefly, TMT reagents were dissolved in anhydrous acetonitrile. Labeling reaction was carried out by incubation of tryptic peptides with the TMT reagents for $1 \mathrm{~h}$ at room temperature, and the reaction was quenched with hydroxylamine. TMT-labeled peptides were desalted using the stage tips.

For LC-MS/MS analysis, the digestion product was separated by a 65 min gradient elution at a flow rate $0.250 \mu \mathrm{L} / \mathrm{min}$ with an EASY-nLCII ${ }^{\mathrm{TM}}$ integrated nanoHPLC system (Proxeon, Denmark) which was directly interfaced with a Thermo LTQ-Orbitrap mass spectrometer. The analytical column was a home-made fused silica capillary column (75 $\mu \mathrm{m}$ ID, $150 \mathrm{~mm}$ length; Upchurch, Oak Harbor, WA) packed with C-18 resin (300 ̊, $5 \mu \mathrm{m}$, Varian, Lexington, MA). Mobile phase A consisted of $0.1 \%$ formic acid, and mobile phase $B$ consisted of $100 \%$ acetonitrile and $0.1 \%$ formic acid. The LTQ-Orbitrap mass spectrometer was operated in the data-dependent acquisition mode using Xcalibur 2.0.7 software and there was a single full-scan mass spectrum in the Orbitrap ( $\mathrm{m} / \mathrm{z} 400$ to $\mathrm{m} / \mathrm{z} 1800,30,000$ resolution) followed by 20 data-dependent MS/MS scans in the ion trap at 35\% normalized collision energy (CID). The MS/ MS spectra from each LC-MS/MS run were searched against the selected database using an in-house Proteome Discovery searching algorithm. For quantitation by TMT labeling, TMT-labeled peptides were analyzed by nano-LC-MS/MS with a Q Exactive mass spectrometer that was also operated in the data-dependent acquisition mode using the Xcalibur 2.1.2 software and there was a single full-scan mass spectrum in an Orbitrap (m/z 350 to $\mathrm{m} / \mathrm{z} 1600 \mathrm{Da}$ ) followed by $10 \mathrm{MS} / \mathrm{MS}$ scans. The MS/ MS spectra from each LC-MS/MS run were analyzed using Proteome Discoverer (Version 1.3) for protein identification and quantitation. Intensity ratios of the TMT reporter ions were used to determine relative concentrations of labeled proteins.

The search criteria were as follows: full tryptic specificity was required; one missed cleavages was allowed; carbamidomethylation was set as fixed modification; oxidation (M) was set as variable modification; precursor ion mass tolerances were set at $10 \mathrm{ppm}$ for all MS acquired in the Orbitrap mass analyzer; and the fragment ion mass tolerance was set at $0.8 \mathrm{Da}$ for all MS/ MS spectra acquired in the linear ion trap. A proteins was designated as a "hit" only when 2 or more unique peptides with high confidence scores $($ FDR $<1 \%)$ were identified and their corresponding MS/MS spectra were manually inspected. When several proteins matched the same sets of peptides, only the proteins with the greater percentage of coverage was selected. Significance was regarded only when the ratio of spectral counts between two groups were more than 2 or less than 0.5 .

\section{DNA Fragment Assay}

DNA fragment assay was performed following the procedure described by Mazars et al [37]. Briefly, cells were washed with PBS twice and collected by centrifugation. Cells were suspended in $250 \mu \mathrm{l}$ lysis buffer (1\% NP-40, $20 \mathrm{mM}$ EDTA, $50 \mathrm{mM}$ Tris- $\mathrm{HCl}, \mathrm{pH}$ 7.5). The supernatants were collected by centrifugation for $5 \mathrm{~min}$ at $1,600 \times \mathrm{g}$. The supernatant was incubated with $0.71 \mathrm{mg} /$ $\mathrm{ml}$ RNase A for $2 \mathrm{~h}$ at $56^{\circ} \mathrm{C}$. Then $100 \mu \mathrm{g} / \mathrm{ml}$ pronase $\mathrm{E}$ was added and incubated with the supernatants overnight at $37^{\circ} \mathrm{C}$. DNA fragments were precipitated with 0.5 volumes of $10 \mathrm{M}$ ammonium acetate and 2 volumes of ethanol at $-20^{\circ} \mathrm{C}$ for $12 \mathrm{~h}$ and centrifugated for $15 \mathrm{~min}$ at $15,000 \times \mathrm{g}$. The precipitate was washed with $70 \%$ ethanol and resuspended in loading buffer. Electrophoresis was performed in $0.5 \times$ Tris-borate-EDTA buffer for $30 \mathrm{~min}$.

\section{Flow Cytometry}

Cells were spun down at $1000 \times \mathrm{g}$ for $5 \mathrm{~min}$. The medium was discarded and washed with PBS twice. Cells were resuspended in $75 \%$ ethanol, vortexed to $\operatorname{mix}$ briefly, and fixed at $4^{\circ} \mathrm{C}$ overnight. After vortex, the fixed cells were re-suspended with PBS solution containing Propidium Iodide (PI) $(50 \mu \mathrm{g} / \mathrm{ml})$, followed by RNaseA treatment $(1 \mathrm{mg} / \mathrm{ml})$ for $30 \mathrm{~min}$ at $37^{\circ} \mathrm{C}$ and analyzed with a BD FACSCalibur ${ }^{\mathrm{Tm}}$ Flow Cytometer using $488 \mathrm{~nm}$ excitation and a $515 \mathrm{~nm}$ bandpass filter for fluorescein detection and a filter $>560 \mathrm{~nm}$ for PI detection. Dot plots and histograms were analyzed by CellQuest Pro software (BD Biosciences, Heidelberg, Germany).

\section{Western Blot Analysis}

Untreated- and azacytidine treated-cells were collected and lysed on ice with Biyuntian cell lysis buffer containing $20 \mathrm{mM}$ Tris ( $\mathrm{pH} 7.5$ ), $150 \mathrm{mM} \mathrm{NaCl}, 1 \%$ Triton X-100, and sodium pyrophosphate, ß-glycerophosphate, EDTA, and $\mathrm{Na}_{3} \mathrm{VO}_{4}$ for Western and IP supplied with the protease inhibitor cocktail. The supernatants were collected after centrifugation at 14,000 $\times \mathrm{g}$ for $10 \mathrm{~min}$ at $4^{\circ} \mathrm{C}$. Protein concentrations were determined using the BCA protein assay kit. Proteins were separated on a $12 \%$ SDS-PAGE gel and transferred onto 
a PVDF transfer membrane by electroblotting. After blocking with $5 \%$ nonfat milk for $2 \mathrm{~h}$ at room temperature, the membrane was incubated overnight at $4^{\circ} \mathrm{C}$ with $1000 \times$ diluted primary antibody, washed with PBST buffer for 3 times, then incubated with $1000 \times$ diluted anti-mouse or anti-rabbit secondary antibody labeled with HRP at room temperature for $2 \mathrm{~h}$. The membrane was further washed with PBST buffer 3 times and developed using the Enlight Kit (Engreen, China). Glyceraldehyde 3-phosphate dehydrogenase $(\mathrm{GAPDH})$ was detected with anti- GAPDH antibody as an internal control.

\section{Quantitative real-time PCR (qPCR)}

Cells were harvested after being treated with azacytidine for different periods of time. Total RNA was extracted by the SV Total RNA Isolation System. cDNA was synthesized from $4 \mu \mathrm{g}$ total RNA using the GoScript ${ }^{\mathrm{TM}} \mathrm{Re}$ verse Transcription System. All qPCR was performed using the Roche LightCycler ${ }^{\circledast}$ 480II Detection System with SYBR green incorporation according to the manufacturer's instructions. The primers were either designed by using the Primer Premier 5 software or from Primer Bank (http://pga.mgh.harvard.edu/primerbank/). To prevent amplification of genomic DNA, all target primers span exon-exon junctions. The specific PCR products were confirmed by melting curve analysis. Relative expression was analyzed using the $2^{-\Delta \Delta C t}$ method. Primer sequences for qPCR are listed in Additional file 1: Table S1.

\section{Co-immunoprecipitation}

Cells were lysed with Biyuntian cell lysis buffer for Western and IP supplied with the protease inhibitor cocktail. The protein concentrations of the cell lysates were determined using a BCA assay. The protein A/G agarose beads were washed three times with cell lysis buffer. $2 \mathrm{mg}$ of the cell lysate was incubated with $6 \mu \mathrm{g}$ antibovine albumin antibody and $20 \mu \mathrm{l}$ protein A/G agarose beads overnight at $4^{\circ} \mathrm{C}$. The beads were centrifuged at $1000 \times \mathrm{g}$ for $1 \mathrm{~min}$ and washed three times with the cell lysis buffer, and proteins bound to the Protein A/G agarose beads were then eluted by boiling the beads for $5 \mathrm{~min}$ in $1 \times$ SDS loading buffer. Each eluent was separated by 1D SDS-PAGE followed by western blot analysis.

\section{Detection of Reactive Oxygen Species (ROS) in Untreated and Azacytidine-treated Cells}

ROS in untreated and azacytidine-treated cells was detected using an Image-iT $\mathrm{T}^{\mathrm{TM}}$ LIVE Green Reactive Oxygen Species Detection Kit (Molecular Probes, Inc. Eugene, OR) following the manufacturer's instructions. Briefly, the cells were collected by centrifugation and washed once with warm $\mathrm{HBSS} / \mathrm{Ca} / \mathrm{Mg}$. Cells were resuspended with $500 \mu \mathrm{l}$ of the $25 \mu \mathrm{M}$ carboxy- $\mathrm{H}_{2}$ DCFDA working solution for $25 \mathrm{~min}$ at $37^{\circ} \mathrm{C}$, followed by addition of the Hoechst 33342 reagent to the reaction mixture at a final concentration of $1.0 \mu \mathrm{M}$ and incubation for $5 \mathrm{~min}$. The final products were washed gently with $1 \mathrm{ml} \mathrm{HBSS} / \mathrm{Ca} / \mathrm{Mg}$ immediately followed by imaging with Zeiss 710 Confocal Microscopy.

\section{Results and discussion}

Azacytidine induces myeloma cell necrosis through oxidative stress

Three myeloma cell lines U266, NCI-H929, and RPMI8226 were treated with azacytidine at different concentrations. All three cell lines showed the identical morphological changes upon azacytidine treatment. FACS analysis showed that the percentage of necrotic cells was $22 \%$ when cells were treated with $5 \mu \mathrm{M}$ azacytidine for $24 \mathrm{~h}$, increasing to $38 \%$ when treated with $80 \mu \mathrm{M}$ azacytidine for $24 \mathrm{~h}$ (Figure 1). Morphological features of the dying cells were consistent with the cell necrosis. Images of cell morphology in untreated, hydrogen peroxide- and azacytidine-treated cells are shown in Figure $2(\mathrm{a}-\mathrm{c})$, respectively. The hydrogen peroxide- and azacytidine-treated myeloma cells displayed characteristic features of necrosis, including cell swelling, translucent cytoplasm, cell membrane disruption, pyknotic nuclei, and excessive cellular debris. The DNA content of necrotic cells was analyzed by gel

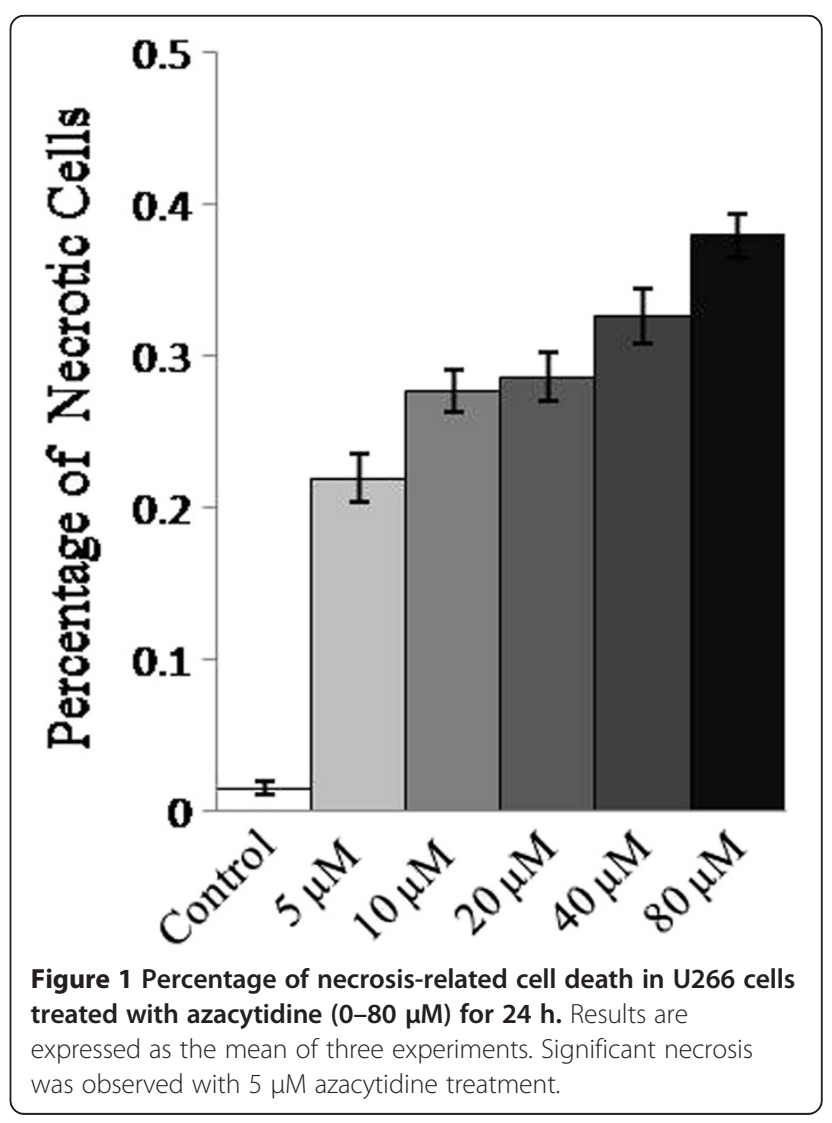



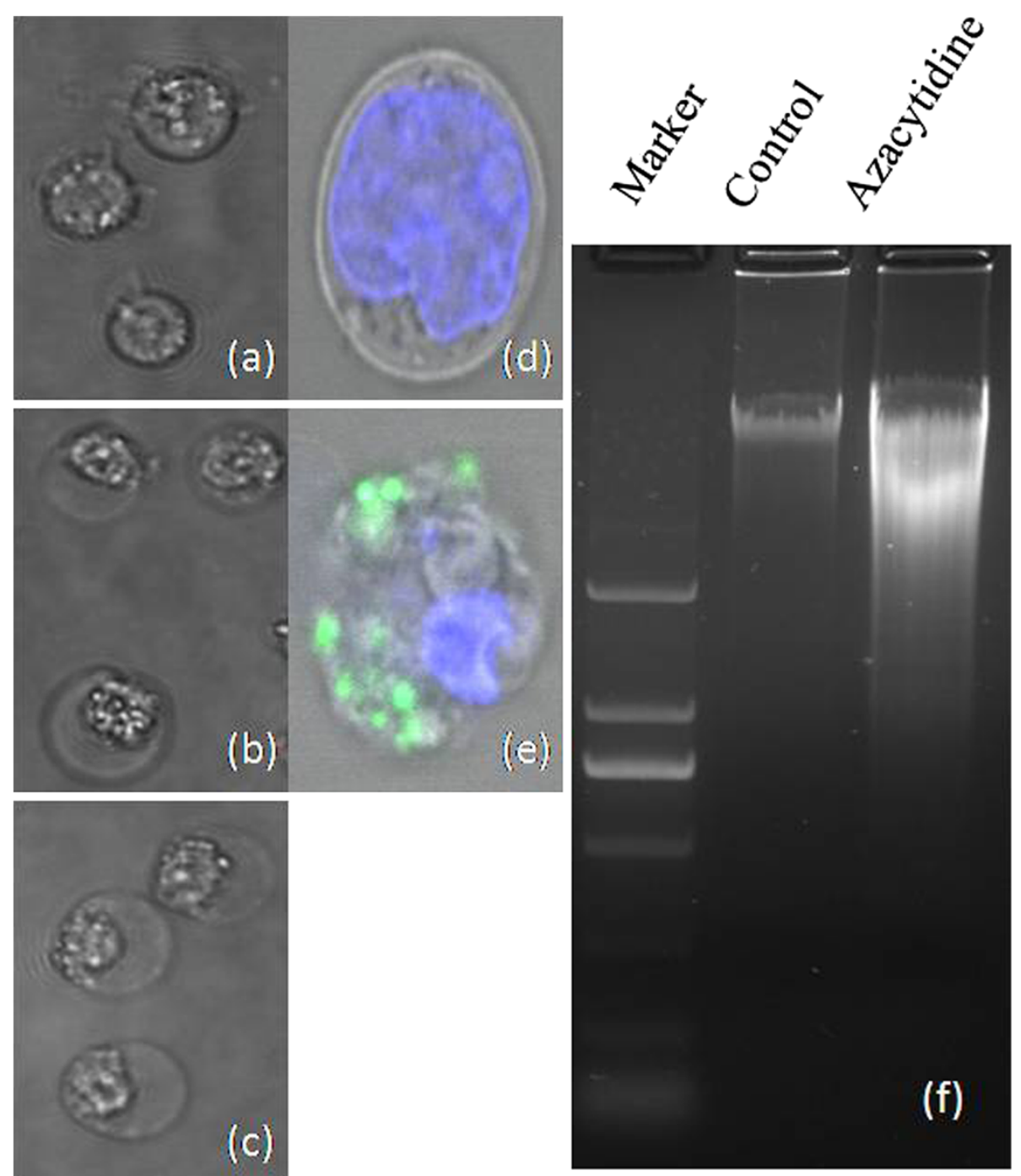

Figure 2 Morphologic images of myeloma cells. (a) untreated cells; (b) $100 \mu \mathrm{M}$ azacytidine-treated cells for 24 h; and (c) $\mathrm{H}_{2} \mathrm{O}_{2}$-treated U266 cells; All images were captured by Olympus IX2-UCB 60X inverted microscopy; (d-e) detection of ROS in untreated and azacytidine-treated U266 cells using the Image-iT LIVE Reactive Oxygen Species (ROS) Kit. Cells were labeled with carboxy- $\mathrm{H}_{2} \mathrm{DCFDA}$, which exhibited green fluorescence when reacted with ROS, and nuclei were stained with blue-fluorescent Hoechst 33342. (d) untreated U266 cells; and (e) azacytidine-treated cells; and (f) gel electrophoresis of DNA from untreated and azacytidine-treated myeloma cells.

electrophoresis. The gel image of DNA for untreated and azacytidine-treated cells (Figure 2(f)) shows that DNA from azacytidine-treated cells exhibited a random and general cleavage pattern and produced a smear that further confirmed that azacytidine-induced cell death occurs mainly via necrosis. The above data suggests that oxidative stress may cause necrosis in azacytidine- or hydrogen peroxide-treated cells. To confirm that ROS contributes to azacytidine induced cell necrosis, an Image-iT LIVE Reactive Oxygen Species (ROS) Kit was used to detect ROS in the untreated and azacytidinetreated cells. Cells were labeled with carboxy- $\mathrm{H}_{2}$ DCFDA, which fluoresces when oxidized by ROS, and nuclei were stained with blue-fluorescent Hoechst 33342. The azacytidine-treated cells exhibited much stronger green fluorescence (Figure 2(e)) in comparison to untreated cells (Figure 2(d)), indicating that azacytidine induced a significant increase in ROS.

\section{Proteomic analysis and identification of cell-bound albumin in myeloma cell necrosis}

Next, proteomic analysis was carried out on the necrotic myeloma cells. An equal amount of proteins $(30 \mu \mathrm{g})$ from untreated- and azacytidine-treated U266 cells were separated by 1D SDS-PAGE (Figure 3). Differentially expressed proteins were immediately visible in the gel band circled with a square. The intensity of the band at about $70 \mathrm{kDa}$ showed the largest change between 


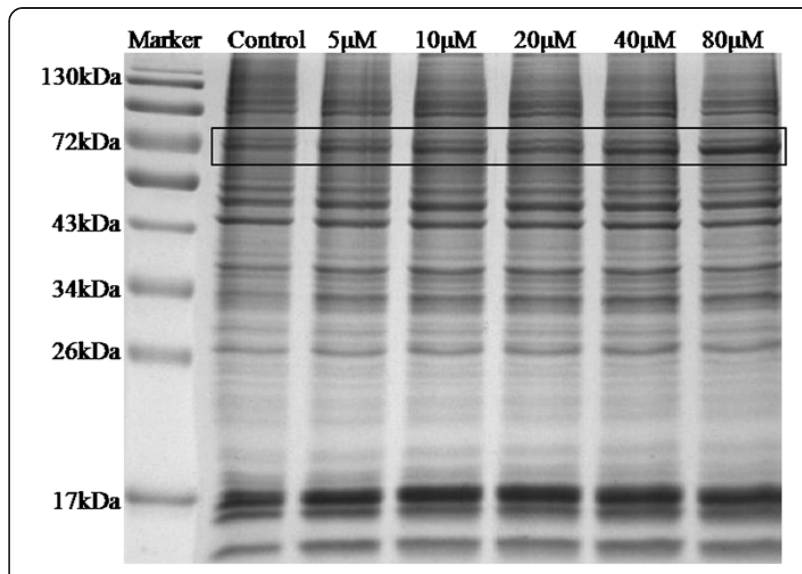

Figure 3 The 1D SDS-PAGE gel image of untreated and $24 \mathrm{~h}$, azacytidine-treated myeloma cells. Lane 1 , molecular weight markers; Lane 2, proteins from untreated cells; Lane 3, proteins from $5 \mu \mathrm{M}$ azacytidine-treated cells; Lane 4, proteins from $10 \mu \mathrm{M}$ azacytidine-treated cells; Lane 5, proteins from $20 \mu \mathrm{M}$ azacytidinetreated cells; Lane 6, proteins from $40 \mu \mathrm{M}$ azacytidine-treated cells; and Lane 7, proteins from $80 \mu \mathrm{M}$ azacytidine-treated cells;. The band with the most differentially expressed proteins was marked with a square. untreated- and azacytidine-treated samples and become more intense with higher concentrations of azacytidine. The gel band was analyzed and the major protein was identified in this band as human albumin, production of which is a hallmark of hepatocytes. Previous studies have shown that monocytes were capable of differentiation into hepatocytes under different conditions, and also that microglial cells in brain synthesized albumin [38-41]. In order to determine whether the cell-bound albumin originated from azacytidine-treated myeloma cells, a human albumin-specific antibody was used for western blot analysis. However, the antibody not only recognized the proteins in the $70 \mathrm{kDa}$ band, but it also recognized bovine serum albumin (data not shown), promoting us to verify the MS/MS spectra of tryptic peptides matched those of human albumin. In fact, MS/MS spectra matched to human albumin by searching a human protein database also matched to sequences of tryptic peptides of bovine serum albumin (BSA). Furthermore, many unidentified MS/MS spectra also matched to peptide sequences of BSA. One of spectra is shown in Additional file 2: Figure S1. Indeed, searching a bovine protein database led to identification of BSA with sequence coverage of $86 \%$ of BSA sequence, demonstrating that BSA was enriched in necrotic cells. Furthermore, the intense band was no longer visible by $1 \mathrm{D}$ SDS-PAGE when myeloma

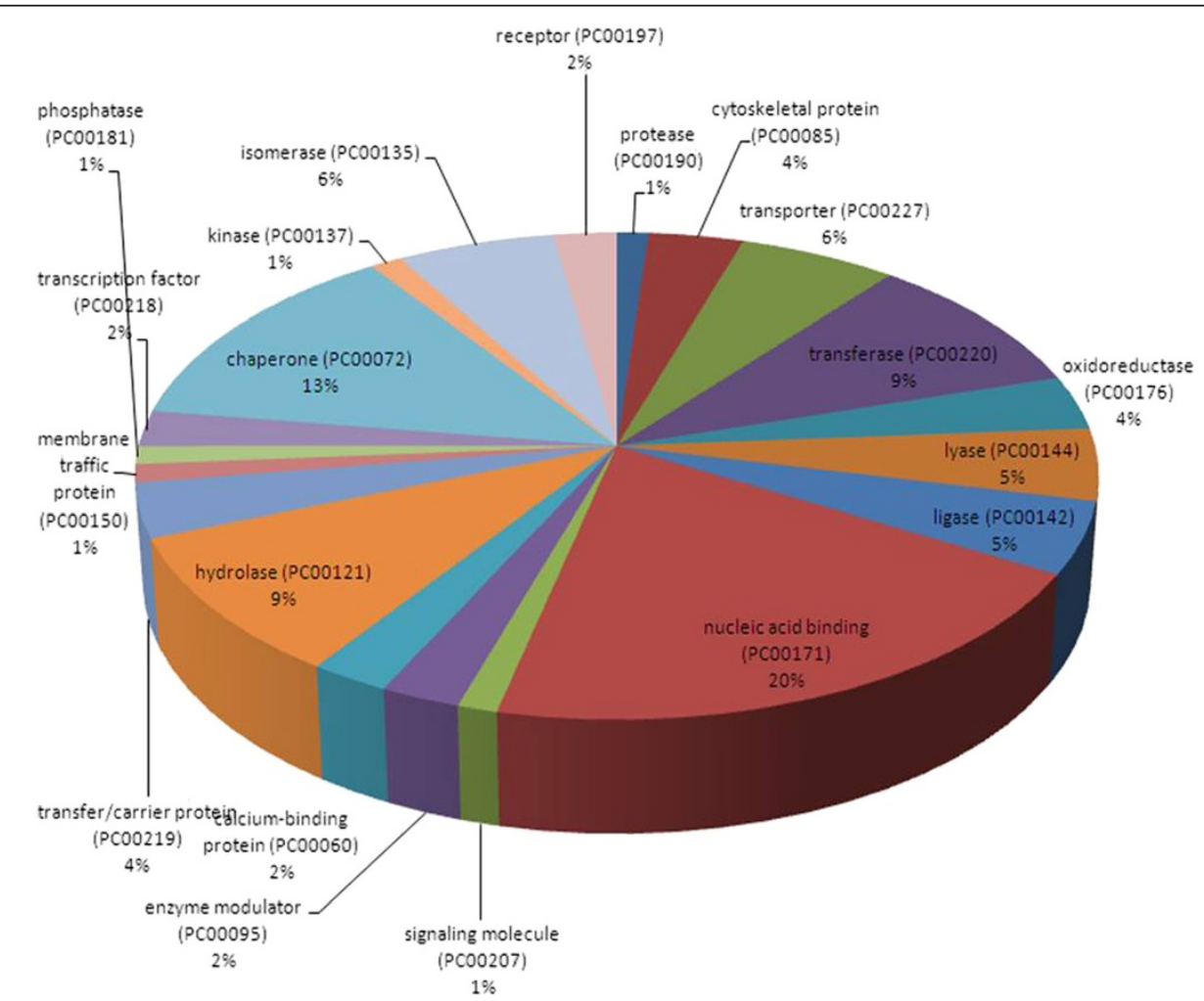

Figure 4 Functional classification of differentially regulated proteins with PANTHER (http://www.pantherdb.org). The numbers of proteins related with each category are shown in brackets. 
cells were cultured in serum-free medium and treated with $100 \mu \mathrm{M}$ azacytidine, confirming that BSA originated from cell culture medium.

Using western blot analysis, we confirmed that enrichment of cell-bound albumin was a concentrationdependent event Additional file 3: Figure S2 (a)). The intensity of the BSA band became more intense when cells were treated with higher concentrations of azacytidine for $24 \mathrm{~h}$. Moreover, western blotting also shows the up-regulation of HSP60 when cells were treated with higher concentrations of azacytidine. A recent study has shown that HSP60 localizes in the tumor cell plasma membrane associated with lipid rafts [42]. In order to determine whether BSA binds to HSP60 in necrotic myeloma cells, we used an anti-BSA antibody to immune-precipitate BSA and associated proteins from untreated and azacytidine-treated myeloma cells. Immunoprecipitated proteins were separated and probed with anti-HSP60 antibodies, and western blot analysis showed that HSP60 was co-immunoprecipitated by an anti-BSA antibody (Additional file 3: Figure S2 (b)). An early study shows that the cell-bound albumin binds to peptidoglycan-, lipopolysacchride-, and lipoteichoic acid in lymphocytes and macrophages [43]. Our data indicate that HSP60 is an additional binding partner of the cell-bound albumin.

A similar protein band pattern by 1D SDS-PAGE was exhibited in Additional file: 4: Figure S3 for U266 cells treated with hydrogen peroxide, showing the characteristic band of enriched cell-bound albumin at about $70 \mathrm{kDa}$. Moreover, enrichment of BSA was observed in other myeloma cell lines RPMI8226 and NCI-H929 when they were treated with azacytidine (Additional file 5: Figure S4). It is worth mentioning that enrichment of albumin is not observed in azacytidine-treated nonhematopoietic cell lines including A549, A2780, and HUH-7 from lung, ovarian, and liver cancer, respectively. Taken together, out data suggest that enrichment of cellbound albumin was unique to oxidative stress inducednecrosis in myeloma cell lines.

\section{Oxidative stress-induced over-expression of ER- and mitochondrial-specific chaperones in necrotic myeloma cells}

We also identified changes of expression levels in other proteins in azacytidine-treated cells. Using label-free quantitation method by spectra counts and the extracted ion current, we showed that expression levels of 79 proteins were changed upon azacytidine treatment. These proteins participate in diverse cellular activities including transporting, nucleic acid binding, hydrolase activities, calcium-binding, membrane trafficking, chaperoning, and receptor binding (Figure 4), in which 17 proteins interact with nucleic acid and 11 proteins are molecular chaperones. Twenty nine up-regulated and 50 downregulated proteins are listed in Table 1 and Table 2, respectively. Nineteen up-regulated proteins are known ER- and mitochondrialspecific proteins. ER is a multifunctional organelle that plays an essential role in protein folding, assembly and quality control of secretory and membrane proteins, disulfide bond formation, glycosylation, lipid biosynthesis, $\mathrm{Ca}^{2+}$ storage and signaling. Significant changes of ER- and mitochondrial proteins indicate that they are main targets of azacytidineinduced oxidative stress.

\section{Table 1 Up-regulated proteins after treatment with $100 \mu \mathrm{M}$ azacytidine}

\begin{tabular}{|c|c|c|}
\hline \multicolumn{2}{|c|}{ Up regulated proteins } & \multirow{2}{*}{$\frac{\text { Fold changes }}{2.4}$} \\
\hline IPI00784154 & $60 \mathrm{kDa}$ heat shock protein, mitochondrial & \\
\hline IPI00010796 & Protein disulfide-isomerase & 2.0 \\
\hline IPI00009904 & Protein disulfide-isomerase A4 & 1.6 \\
\hline IPI00020599 & Calreticulin & 1.7 \\
\hline IPI00027230 & Endoplasmin & 3.0 \\
\hline IPI00941747 & Calnexin & 2.6 \\
\hline IPI00025874 & $\begin{array}{l}\text { Dolichyl-diphosphooligosaccharide- } \\
\text { protein glycosyltransferase subunit } 1\end{array}$ & 2.1 \\
\hline IPI00453473 & Histone $\mathrm{H} 4$ & 2.0 \\
\hline IPI00556485 & RPLP0 protein & 1.6 \\
\hline IPI00216691 & Profilin-1 & 2.5 \\
\hline IPI00018206 & Aspartate aminotransferase, mitochondrial & 2.8 \\
\hline IPI00440493 & ATP synthase subunit alpha, mitochondrial & 2.8 \\
\hline IPI00020416 & Tripeptidyl-peptidase 2 & 1.6 \\
\hline IPI00291006 & Malate dehydrogenase, mitochondrial & 3.3 \\
\hline IPI00339274 & Histone $\mathrm{H} 2 \mathrm{~A}$ type $2-\mathrm{C}$ & 2.7 \\
\hline IPI00642982 & LONP1 protein & 2.3 \\
\hline IPI00018534 & Histone $\mathrm{H} 2 \mathrm{~B}$ type $1-\mathrm{L}$ & 2.5 \\
\hline IPI00294398 & $\begin{array}{l}\text { Isoform } 1 \text { of Hydroxyacyl-coenzyme A } \\
\text { dehydrogenase, mitochondrial }\end{array}$ & 1.8 \\
\hline IPI00006482 & $\begin{array}{l}\text { Isoform Long of Sodium/potassium- } \\
\text { transporting ATPase subunit alpha-1 }\end{array}$ & 2.1 \\
\hline IPI00030363 & $\begin{array}{l}\text { Acetyl-CoA acetyltransferase, } \\
\text { mitochondrial }\end{array}$ & 1.8 \\
\hline IPI00303476 & ATP synthase subunit beta, mitochondrial & 3.4 \\
\hline IPI00216308 & $\begin{array}{l}\text { Voltage-dependent anion-selective } \\
\text { channel protein } 1\end{array}$ & 3.3 \\
\hline IPI00017334 & Prohibitin & 2.5 \\
\hline IPI00001539 & 3-ketoacyl-CoA thiolase, mitochondrial & 2.0 \\
\hline IPI00008529 & 605 acidic ribosomal protein P2 & 1.8 \\
\hline IPI00013808 & Alpha-actinin-4 & 1.9 \\
\hline IPI00413611 & DNA topoisomerase 1 & 1.8 \\
\hline IPI00759715 & $\begin{array}{l}\text { Isoform Cytoplasmic of } \\
\text { Fumaratehydratase, mitochondrial }\end{array}$ & 1.6 \\
\hline IPI00646304 & Peptidyl-prolylcis-trans isomerase B & 1.7 \\
\hline
\end{tabular}


Table 2 Down-regulated proteins after treatment with $100 \mu \mathrm{M}$ azacytidine

\begin{tabular}{|c|c|c|}
\hline \multicolumn{2}{|c|}{ Down regulated proteins } & \multirow{2}{*}{$\begin{array}{c}\begin{array}{r}\text { Fold } \\
\text { chang }\end{array} \\
0.5\end{array}$} \\
\hline IPI00003865 & $\begin{array}{l}\text { Isoform } 1 \text { of Heat shock cognate } \\
71 \mathrm{kDa} \text { protein }\end{array}$ & \\
\hline IPI00414676 & Heat shock protein HSP 90-beta & 0.7 \\
\hline IPI00784295 & Isoform 1 of Heat shock protein HSP 90-alpha & 0.6 \\
\hline IPI00220740 & Isoform 2 of Nucleophosmin & 0.2 \\
\hline IPI00018465 & T-complex protein 1 subunit eta & 0.7 \\
\hline IPI00179330 & Ubiquitin-40S ribosomal protein S27a & 0.4 \\
\hline IPI00985384 & ATP-dependent RNA helicase DDX3X isoform 3 & 0.2 \\
\hline IPI00027547 & Dermcidin & 0.2 \\
\hline |PI00376143 & $\begin{array}{l}\text { DNA replication licensing factor } \\
\text { MCM7 isoform } 2\end{array}$ & 0.3 \\
\hline IPI00786995 & $\begin{array}{l}\text { DNA-dependent protein kinase } \\
\text { catalytic subunit-like }\end{array}$ & 0.2 \\
\hline IPI00002966 & Heat shock $70 \mathrm{kDa}$ protein 4 & 0.4 \\
\hline IPI00027107 & elongation factor Tu, mitochondrial precursor & 0.4 \\
\hline IPI00026781 & Fatty acid synthase & 0.4 \\
\hline IPI00015018 & Inorganic pyrophosphatase & 0.5 \\
\hline IPI00008557 & $\begin{array}{l}\text { Insulin-like growth factor } 2 \text { mRNA-binding } \\
\text { protein } 1\end{array}$ & 0.4 \\
\hline IPI00000816 & Isoform 1 of 14-3-3 protein epsilon & 0.5 \\
\hline IPI00658000 & $\begin{array}{l}\text { Isoform } 1 \text { of Insulin-like growth factor } \\
2 \text { mRNA-binding protein } 3\end{array}$ & 0.1 \\
\hline IPI00455383 & Isoform 2 of Clathrin heavy chain 1 & 0.5 \\
\hline IPI00883762 & $\begin{array}{l}\text { Isoform } 2 \text { of Cytosolic acyl coenzyme A } \\
\text { thioester hydrolase }\end{array}$ & 0.1 \\
\hline IPI00025273 & $\begin{array}{l}\text { Isoform Long of Trifunctional purine } \\
\text { biosynthetic protein adenosine-3 }\end{array}$ & 0.4 \\
\hline IPI00216230 & $\begin{array}{l}\text { Lamina-associated polypeptide 2, } \\
\text { isoform alpha }\end{array}$ & 0.5 \\
\hline IPI00170935 & Leucine-rich repeat-containing protein 47 & 0.1 \\
\hline IPI00017297 & Matrin-3 & 0.1 \\
\hline IPI00016610 & Poly(rC)-binding protein 1 & 0.5 \\
\hline IPI00017617 & Probable ATP-dependent RNA helicase DDX5 & 0.5 \\
\hline IPI00550451 & $\begin{array}{l}\text { Serine/threonine-protein phosphatase } \\
\text { PP1-alpha catalytic subunit }\end{array}$ & 0.2 \\
\hline IPI00947285 & suprabasin isoform 1 precursor & 0.3 \\
\hline IPI00216049 & $\begin{array}{l}\text { Isoform } 1 \text { of Heterogeneous nuclear } \\
\text { ribonucleoprotein } \mathrm{K}\end{array}$ & 0.1 \\
\hline IPI01011912 & Phosphoglycerate kinase & 0.5 \\
\hline IPI00549725 & Phosphoglyceratemutase 1 & 0.2 \\
\hline IPI00645452 & Tubulin, beta & 0.3 \\
\hline IPI00179964 & $\begin{array}{l}\text { Isoform } 1 \text { of Polypyrimidine } \\
\text { tract-binding protein } 1\end{array}$ & 0.3 \\
\hline IPI00217465 & Histone H1.2 & 0.4 \\
\hline IPI00783271 & $\begin{array}{l}\text { Leucine-rich PPR motif-containing } \\
\text { protein, mitochondrial }\end{array}$ & 0.5 \\
\hline IPI00219365 & Moesin & 0.6 \\
\hline
\end{tabular}

Table 2 Down-regulated proteins after treatment with $100 \mu \mathrm{M}$ azacytidine (Continued)

\begin{tabular}{lll}
\hline IPI00396485 & Elongation factor 1-alpha 1 & 0.4 \\
IPI00419258 & High mobility group protein B1 & 0.3 \\
IPI00031812 & Nuclease-sensitive element-binding protein 1 & 0.3 \\
IPI00465439 & Fructose-bisphosphatealdolase A & 0.5 \\
IPI00217223 & Multifunctional protein ADE2 & 0.4 \\
IPI00550363 & Transgelin-2 & 0.5 \\
IPI00917777 & 116 kDa U5 small nuclear ribonucleoprotein & \\
& component isoform b & 0.5 \\
IPI00100160 & Isoform 1 of Cullin-associated & \\
& NEDD8-dissociated protein 1 & 0.5 \\
IPI00793443 & Isoform 1 of Importin-5 & 0.4 \\
IPI00449049 & Poly [ADP-ribose] polymerase 1 & 0.6 \\
IPI00007797 & Fatty acid-binding protein, epidermal & 0.4 \\
IPI00398625 & Hornerin & 0.4 \\
IPI00843975 & Ezrin & 0.6 \\
IPI00465248 & Isoform alpha-enolase of Alpha-enolase & 0.5 \\
IPI00645078 & Ubiquitin-like modifier-activating enzyme 1 & 0.4 \\
\hline
\end{tabular}

Five known mitochondrial and ER-chaperones HSP60, protein disulfide isomerase (PDI), endoplasmin, calreticulin, and calnexin were all upregulated in U266 cells upon azacytidine treatment as indicated by changes of spectra counts (Figure 5(a)), showing that expression level of HSP60 has three-fold increase in necrotic cells. Up-regulation of HSP60 was also confirmed by western blotting (Additional file 3: Figure S2 (a)). Protein abundance index (PAI) was calculated based on the number of observed peptides per protein normalized by the theoretical number of peptides (Additional file 6: Table S2), showing that the relative concentration of HSP60 is 2 times higher than those of other four chaperones. It has been shown that HSP60 is essential in the synthesis and transportation of essential mitochondrial proteins [44] and that HSP60 is up-regulated to protect cellular survival under toxic or stressful circumstances [45-47]. Our data demonstrates that expression level of HSP60 is highly up-regulated under oxidative stress, suggesting HSP60 may serve as a new target in myeloma treatment.

PDI catalyzes formation and breakage of disulfide bonds for proteins to achieve their fully folded state and aids wrongly folded proteins to reach a correctly folded state as a chaperone $[48,49]$. Endoplasmin chaperone functions in the processing and transport of secreted proteins in ER and possesses the ATPase activity and calcium-binding property. Calreticulin is a lectin-like, calcium binding ER-specific chaperone that binds to misfolded proteins and prevents them from being exported from the ER to the Golgi apparatus. Overexpression of calreticulin in many cancer cells promotes 


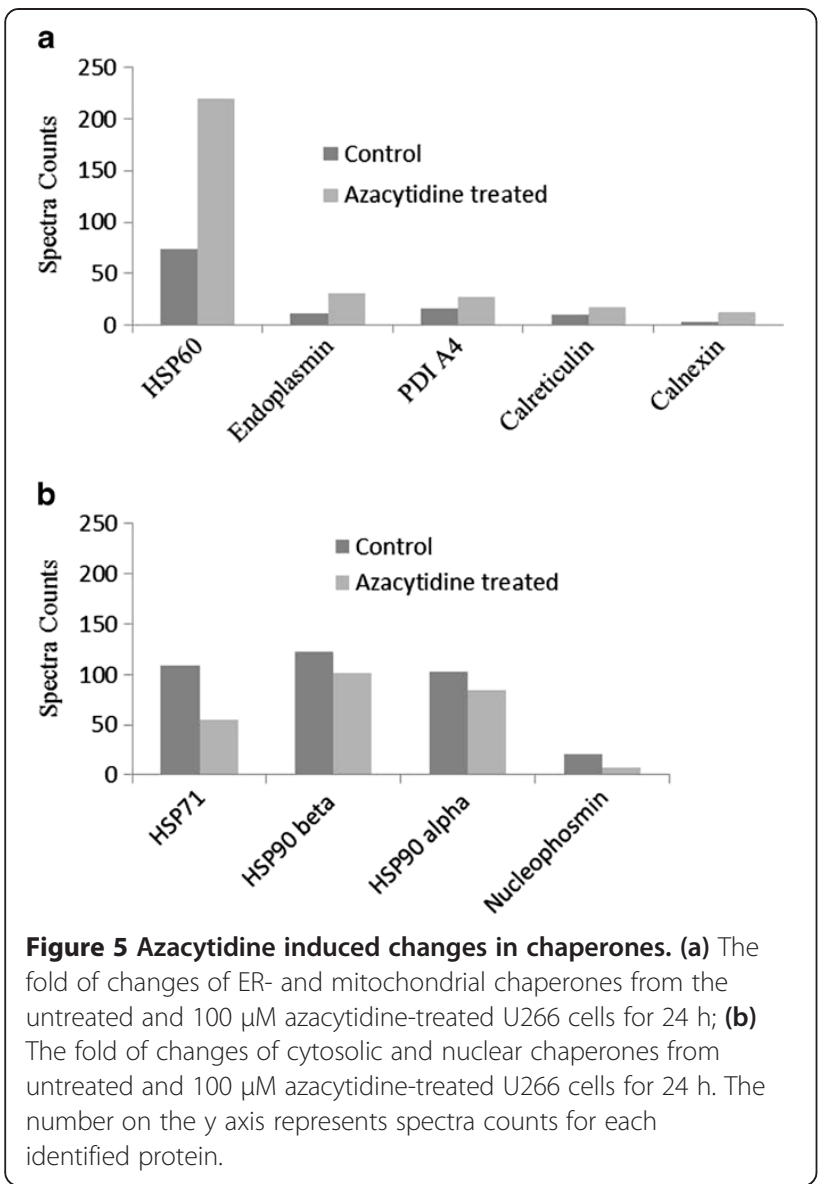

macrophages to engulf hazardous cancerous cells [50]. Azacytidine also induces up-regulation of calnexin (CNX), whose main function is to assist protein folding and quality control. Calreticulin, calnexin, and ERp57 constitute the calreticulin/calnexin cycle functioning in the quality control of transmembrane and secreted glycoproteins in ER. Up-regulation of ER-specific chaperones indicates that oxidative stress activates intracellular signal transduction pathways and induces the transcriptional upregulation of genes to enhance the ER proteinfolding capacity and quality control. Azacytidine induced up-regulation of mitochondrial and ER-chaperones were also observed in other treated myeloma cells as quantified by TMT labeling (Additional file 7: Table S3).

\section{Necrosis-induced release of HSP71 and HSP90 into the cell medium}

Expression levels in 50 proteins were down-regulated upon azacytidine treatment including 22 nucleusspecific proteins and 21 nucleotide binding proteins. Five chaperones were down-regulated including chaperonin containing TCP1 subunit 7 (eta), HSP71, HSP90 alpha (cytosolic), HSP90 beta, and nucleophosmin 2 (Figure 5(b)). To confirm azacytidine-induced down- regulation of HSP90 and HSP71, qPCR analysis was carried out, and showed that the expression of HSP90 and HSP71 at the mRNA level is down-regulated after azacytidine treatment (Figure 6). HSP71 is the major chaperone involving in protein folding and protects proteins against aggregation in cytosol. Extensive studies have shown that HSP71 is detected outside cells, where it is thought to activate the immune system [51-53]. In order to determine whether necrotic myeloma cells release HSP71 into cell medium, we analyzed proteins in culture medium of untreated and azacytidine-treated cells. Using TMT labeling, we found that relative concentrations of HSP71 and HSP90 were two times higher in medium of necrotic cells than those of untreated cells (Additional file 8: Figure S5), demonstrating enhanced release of HSP71 and HSP90 from necrotic cells into the cell culture medium. HSP71 does not have a consensus sequence for secretion, and the mechanism for translocation of this protein across membranes may involve in the binding of HSP71 with the plasma membrane before release into the extracellular environment. Chaperonin containing TCP-1 is a cytoplasmic protein and plays an important role in folding of alpha and beta tubulin. The expression level of nucleophosmin has the largest decrease upon azacytidine-treatment Figure 5(b). Nucleophosmin 2 is a histone chaperone located in the nucleolus, but it can be translocated to the nucleoplasm in response to serum starvation or drug treatment. Other down-regulated proteins participated in diverse activities such as nucleotide-binding, metabolic processes, and RNA binding (Table 2). Azacytidine is an inhibitor for DNA methyltransferase. We did not determine azacytidine-induced changes in DNA methylation in current study. We hypothesize that changes in gene expressions are attributable to both azacytidine induced epigenetic changes and ROS signaling. Great efforts are

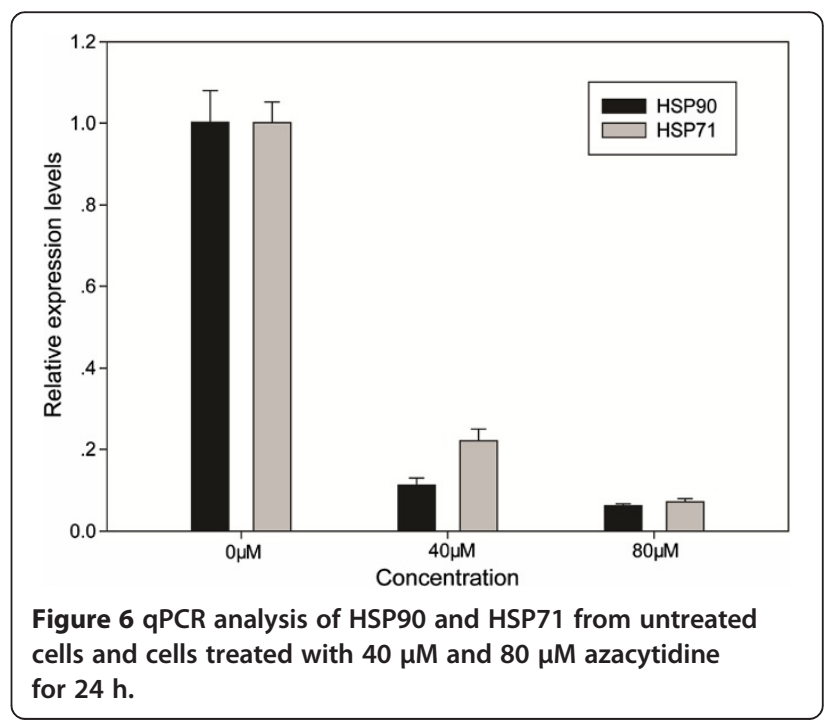


still needed to determine molecule mechanisms of azacytidine induced necrosis in myeloma cells.

\section{Conclusions}

Taken together, our results show that azacytidine and hydrogen peroxide induce necrosis in myeloma cells through oxidative stress, resulting in enrichment of cell-bound albumin and up-regulation of ER- and mitochondrial-specific chaperones and suggesting that mitochondria and ER are major targets of ROS. Expression levels of HSP90 and HSP71 are down-regulated in azacytidine-treated cells, concomitant with enhanced release of these cytosolic chaperones into the cell culture medium. Inhibition of HSP60 may be a new therapeutic approach for myeloma treatment.

\section{Additional files}

Additional file 1: Table S1. Primers used for $\mathrm{QPCR}$ analysis in this work. Additional file 2: Figure S1. The MS/MS spectrum of a doubly charged peptide ion at $\mathrm{m} / \mathrm{z} 863$ for $\mathrm{MH}_{2}^{2+}$ corresponding to the mass of the peptide MPCTEDYLSLILNR) from Bovine serum albumin,with four amino acids difference from human serum albumin.

Additional file 3: Figure S2. Western blot analysis of BSA and HSP60 in azacytidine treated cells. (a) Western blot analysis of HSP60 and BSA from untreated and U266 cells treated with $20 \mu \mathrm{M}, 40 \mu \mathrm{M}$, and $80 \mu \mathrm{M}$ azacytidine for $24 \mathrm{~h}$. Lane 1, before treatment; Lane 2, $20 \mu \mathrm{M}$; Lane 3, $40 \mu \mathrm{M}$; and Lane 4, and $80 \mu \mathrm{M}$. (b) Western blot analysis of HSP60 after anti-BSA antibody-immunoprecipitation.

Additional file 4: Figure S3. The 1D SDS-PAGE gel image of proteins from untreated and $\mathrm{H}_{2} \mathrm{O}_{2}$-treated U266 cells. Lane 1, molecular weight markers; Lane 2, proteins from untreated cells; Lane 3, proteins from $2.5 \mathrm{mM} \mathrm{H}_{2} \mathrm{O}_{2}$-treated U266 cells; Lane 4, proteins from $5 \mathrm{mM} \mathrm{H}_{2} \mathrm{O}_{2-}$ treated cells. The band with differentially expressed proteins was marked with a square.

Additional file 5: Figure S4. The 1D SDS-PAGE gel image of proteins from untreated and azacytidine-treated RPMI8226 and NCl-H929 cells. Lane 1, molecular weight markers; Lane 2, proteins from untreated cells; Lane 3, proteins from $80 \mu \mathrm{M}$ azacytidine-treated RPMl8226 cells; Lane 4, molecular weight markers; Lane 5, proteins from untreated NCl-H929 cells; Lane 6, proteins from $80 \mu \mathrm{M}$ azacytidine-treated NCI-H929 cells. The band with differentially expressed proteins was marked with a square.

Additional file 6: Table S2. Estimated protein abundance index (PAI) of HSP60, PDI, endoplasmin, calreticulin, and calnexin in untreated and $24 \mathrm{~h}$, $100 \mu \mathrm{M}$ azacytidine-treated U266 cells.

Additional file 7: Table S3. Relative concentration ratios of selected proteins in untreated and azacytidine-treated RPMI8226 and NCI-H929 cells as determined by TMT-labeling, respectively.

Additional file 8: Figure S5. MS/MS spectra of TMT-labeled peptides of HSP71 and HSP90. (a) The MS/MS spectrum of a doubly charged ion at $\mathrm{m} / \mathrm{z} 739.89$ for $\mathrm{MH}_{2}^{2+}$ corresponding to the mass of the peptide TMT-labeled FEELNADLFR. The labeled peaks correspond to masses of $y$ and $b$ ions of the modified peptide; (b) The MS/MS spectrum of a triply charged ion at $\mathrm{m} / \mathrm{z} 465.25$ for $\mathrm{MH}_{3}^{3+}$ corresponding to the mass of the TMT-labeled peptide LGIHEDSQNR. The labeled peaks correspond to masses of $y$ and $b$ ions of the modified peptide. Figure inserts show peaks of TMT reporter ions of two labeled peptides.

\section{Competing interests}

We hereby declare that we have no financial or non-financial competing interest.

\section{Authors' contributions}

QTW and HTD designed the study and write the manuscript; EBT and HPT did all proteomic analysis; RHX and CDL participated data analysis. All authors read the draft and approved the final manuscript.

\section{Acknowledgments}

We thank the Cell Biology facility and the Protein Chemistry Facility at the Center for Biomedical Analysis of Tsinghua University for sample analysis. We thank Dr Xiaoyong Jiang for helpful discussions. This work was supported in part by the Center for Life Sciences (Tsinghua University), the National Natural Science Foundation of China (No. 30872391 and 31270871), and MOEC (No. 2012Z02293).

\section{Author details}

'Beijing Chaoyang Hospital affiliated Capital Medical University, Beijing,

China. ${ }^{2}$ School of Life Sciences, Tsinghua University, Beijing, China.

Received: 13 November 2012 Accepted: 7 June 2013

Published: 13 June 2013

\section{References}

1. Palumbo A, Anderson K: Multiple Myeloma. N Eng J Med 2011, 364:1046-1060.

2. Galm O, Wilop S, Reichelt J, Jost E, Gehbauer G, Herman J, Osieka R: DNA methylation changes in multiple myeloma. Leukemia 2004, 18:1687-1692.

3. Walker BA, Wardell CP, Chiecchio L, Smith EM, Boyd KD, Neri A, Davies FE, Ross FM, Morgan GJ: Aberrant global methylation patterns affect the molecular pathogenesis and prognosis of multiple myeloma. Blood 2011, 117:553-562.

4. Salhia B, Baker A, Ahmann G, Auclair D, Fonseca R, Carpten J: DNA methylation analysis determines the high frequency of genic hypomethylation and low frequency of hypermethylation events in plasma cell tumors. Cancer Res 2010, 70:6934-6944.

5. Fenaux P, Mufti GJ, Hellstrom-Lindberg E, Santini V, Finelli C, Giagounidis A, Schoch R, Gattermann N, Sanz G, List A: Efficacy of azacitidine compared with that of conventional care regimens in the treatment of higher-risk myelodysplastic syndromes: a randomised, open-label, phase III study. Lancet Oncol 2009, 10:223-232.

6. Silverman LR, McKenzie DR, Peterson BL, Holland JF, Backstrom JT, Beach C, Larson RA: Further analysis of trials with azacitidine in patients with myelodysplastic syndrome: studies 8421,8921 , and 9221 by the Cancer and Leukemia Group B. J Clin Oncol 2006, 24:3895-3903.

7. Silverman $L R$, Demakos EP, Peterson BL, Kornblith AB, Holland JC, OdchimarReissig R, Stone RM, Nelson D, Powell BL, DeCastro CM: Randomized controlled trial of azacitidine in patients with the myelodysplastic syndrome: a study of the cancer and leukemia group B. $J$ Clin Oncol 2002, 20:2429-2440.

8. Kiziltepe T, Hideshima T, Catley L, Raje N, Yasui H, Shiraishi N, Okawa Y, Ikeda H, Vallet S, Pozzi S: 5-Azacytidine, a DNA methyltransferase inhibitor, induces ATR-mediated DNA double-strand break responses, apoptosis, and synergistic cytotoxicity with doxorubicin and bortezomib against multiple myeloma cells. Mol Cancer Ther 2007, 6:17-18.

9. Chen G, Wang Y, Huang H, Lin F, Wu D, Sun A, Chang H, Feng Y: Combination of DNA methylation inhibitor 5-azacytidine and arsenic trioxide has synergistic activity in myeloma. Eur $J$ Haematol 2009, 82:176-183.

10. Khong T, Sharkey J, Spencer A: The effect of azacitidine on interleukin-6 signaling and nuclear factor- $\mathrm{KB}$ activation and its in vitro and in vivo activity against multiple myeloma. Haematologica 2008, 93:860-869.

11. Zhang Y, Wang Z, Zhang J, Farmer B, Lim SH: Semenogelin I expression in myeloma cells can be upregulated pharmacologically. Leuk Res 2008, 32:1889-1894

12. Edinger AL, Thompson CB: Death by design: apoptosis, necrosis and autophagy. Curr Opin Cell Biol 2004, 16:663-669.

13. Zong WX, Thompson CB: Necrotic death as a cell fate. Genes Dev 2006, $20: 1-15$

14. Golstein P, Kroemer G: Cell death by necrosis: towards a molecular definition. Trends Biochem Sci 2007, 32:37-43.

15. Han J, Zhong CQ, Zhang DW: Programmed necrosis: backup to and competitor with apoptosis in the immune system. Nat Immunol 2011, 12:1143-1149. 
16. Wang $Z$, Jiang $H$, Chen $S, D u F$, Wang $X$ : The mitochondrial phosphatase PGAM5 functions at the convergence point of multiple necrotic death pathways. Cell 2012, 148:228-243

17. Rock KL, Kono H: The inflammatory response to cell death. Annu Rev Pathol 2008, 3:99-126.

18. Jäättelä M, Tschopp J: Caspase-independent cell death in T lymphocytes. Nat Immunol 2003, 4:416-423.

19. Iyer SS, Pulskens WP, Sadler JJ, Butter LM, Teske GJ, Ulland TK, Eisenbarth SC, Florquin S, Flavell RA, Leemans JC: Necrotic cells trigger a sterile inflammatory response through the NIrp3 inflammasome. SCi STKE 2009, 106:20388-20393.

20. Festjens $N$, Vanden Berghe T, Vandenabeele P: Necrosis, a well-orches trated form of cell demise: signalling cascades, important mediators and concomitant immune response. Biochimica et Biophysica Acta (BBA)Bioenergetics 2006, 1757:1371-1387.

21. Basu S, Binder RJ, Suto R, Anderson KM, Srivastava PK: Necrotic but not apoptotic cell death releases heat shock proteins, which deliver a partial maturation signal to dendritic cells and activate the NF-KB pathway. Int Immunol 2000, 12:1539-1546.

22. Basu S, Srivastava PK: Heat shock proteins: the fountainhead of innate and adaptive immune responses. Cell stress \& chaperons 2000, 5:443-451.

23. Lipscomb MF, Masten BJ: Dendritic cells: immune regulators in health and disease. Physiol Rev 2002, 82:97-130.

24. Robert J: Evolution of heat shock protein and immunity. Dev Comp Immunol 2003, 27:449-464.

25. Mark G, Zihai L: Heat-shock proteins in infection-mediated inflammationinduced tumorigenesis. J Hematol Oncol 2009, 30:5.

26. Tsan MF, Gao B: Heat shock protein and innate immunity. Cell Mol Immunol 2004, 1:274-279.

27. Beg AA: Endogenous ligands of Toll-like receptors: implications for regulating inflammatory and immune responses. Trends Immunol 2002 23:509-512.

28. Calderwood SK, Murshid A, Gong J: Heat shock proteins: conditional mediators of inflammation in tumor immunity. Front Immunol 2012, 3:75.

29. Nakamura M, Esumi H, Jin L, Mitsuya $H$, Hata H: Induction of Necrosis in Human Myeloma Cells by Kigamicin. Anticancer Res 2008, 28:37-44.

30. Nair RR, Emmons MF, Cress AE, Argilagos RF, Lam K, Kerr WT, Wang HG, Dalton WS, Hazlehurst LA: HYD1-induced increase in reactive oxygen species leads to autophagy and necrotic cell death in multiple myeloma cells. Mol Cancer Ther 2009, 8:2441-2451.

31. Chandra J: Oxidative stress by targeted agents promotes cytotoxicity in hematologic malignancies. Antioxid Redox Signal 2009, 11:1123-1137.

32. Gao S, Mobley A, Miller C, Boklan J, Chandra J: Potentiation of reactive oxygen species is a marker for synergistic cytotoxicity of MS-275 and 5-azacytidine in leukemic cells. Leuk Res 2008, 32:771-780.

33. Nadasi E, Clark JS, Szanyi I, Varjas T, Ember I, Baliga R, Arany I: Epigenetic Modifiers Exacerbate Oxidative Stress in Renal Proximal Tubule Cells. Anticancer Res 2009, 29:2295-2299.

34. Kregel $\mathrm{KC}$, Zhang $\mathrm{HJ}$ : An integrated view of oxidative stress in aging basic mechanisms, functional effects, and pathological considerations. Am J Physiol Regul Integr Comp Physiol 2007, 292:R18-R36.

35. Patten DA, Germain M, Kelly MA, Slack RS: Reactive oxygen species: stuck in the middle of neurodegeneration. J Alzheimers Dis 2010, 20:357-367.

36. Sitia R, Molteni SN: Stress, protein (mis) folding, and signaling: the redox connection. Sci STKE 2004, 239:27.

37. Mazars A, Lallemand F, Prunier C, Marais J, Ferrand N, Pessah M, Cherqui G, Atfi A: Evidence for a role of the JNK cascade in Smad7-mediated apoptosis. J Biol Chem 2001, 276:36797-36803.

38. Zhao Y, Glesne D, Huberman E: A human peripheral blood monocytederived subset acts as pluripotent stem cells. Proc Natl Acad Sci 2003, 100:2426-2431.

39. Ruhnke $M$, Ungefroren $H$, Nussler A, Martin F, Brulport M, Schormann W, Hengstler JG, Klapper W, Ulrichs K, Hutchinson JA: Differentiation of In Vitro-Modified Human Peripheral Blood Monocytes Into Hepatocyte-like and Pancreatic Islet-like Cells. Gastroenterology 2005, 128:1774-1786.

40. Yan L, Han Y, Wang J, Liu J, Hong L, Fan D: Peripheral blood monocytes from patients with HBV related decompensated liver cirrhosis can differentiate into functional hepatocytes. Am J Hematol 2007, 82:949-954.

41. Ahn SM, Byun K, Cho K, Kim JY, Yoo JS, Kim D, Paek SH, Kim SU, Simpson $\mathrm{RJ}$, Lee B: Human microglial cells synthesize albumin in brain. PLoS One 2008, 3:28-29.
42. Campanella C, Bucchieri F, Merendino AM, Fucarino A, Burgio G, Corona D, Barbieri G, David S, Farina F, Zummo G, De Macario GC, Macario A, Cappello F: The Odyssey of Hsp60 from Tumor Cells to Other Destinations Includes Plasma Membrane-Associated Stages and Golgi and Exosomal Protein-Trafficking Modalities. PLoS One 2012, 7:e42008.

43. Dziarski R: Cell-bound albumin is the 70-kDa peptidoglycan-, lipopolysaccharide-, and lipoteichoic acid-binding protein on lymphocytes and macrophages. J Biol Chem 1994, 269:20431-20436.

44. Koll H, Guiard B, Rassow J, Ostermann J, Horwich A, Neupert W, Hartl FU: Antifolding activity of hsp60 couples protein import into the mitochondrial matrix with export to the intermembrane space. Cell 1992, 68:1163-1175.

45. Calabrese V, Mancuso C, Ravagna A, Perluigi M, Cini C, Marco CD, Allan Butterfield D, Stella AMG: In vivo induction of heat shock proteins in the substantia nigra following L-DOPA administration is associated with increased activity of mitochondrial complex I and nitrosative stress in rats: regulation by glutathione redox state. J Neurochem 2007, 101:709-717.

46. Rossi MR, Somji S, Garrett SH, Sens MA, Nath J, Sens DA: Expression of hsp 27 , hsp 60, hsc 70, and hsp 70 stress response genes in cultured human urothelial cells (UROtsa) exposed to lethal and sublethal concentrations of sodium arsenite. Environ Health Perspect 2002, 110:1225.

47. Chandra D, Choy G, Tang DG: Cytosolic Accumulation of HSP60 during Apoptosis with or without Apparent Mitochondrial Release. J Biol Chem 2007, 282:31289-31301.

48. Wilkinson B, Gilbert HF: Protein disulfide isomerase. Biochimica et Biophysica Acta (BBA)-Proteins. Proteomics 2004, 1699:35-44

49. Gruber CW, Cemazar M, Heras B, Martin JL, Craik DJ: Protein disulfide isomerase: the structure of oxidative folding. Trends Biochem Sci 2006, 31:455-464.

50. Gold LI, Eggleton P, Sweetwyne MT, Van Duyn LB, Greives MR, Naylor SM, Michalak M, Murphy-Ullrich JE: Calreticulin: non-endoplasmic reticulum functions in physiology and disease. FASEB J 2010, 24:665-683.

51. Vega VL, Rodríguez-Silva M, Frey T, Gehrmann M, Diaz JC, Steinem C, Multhoff G, Arispe N, De Maio A: Hsp70 translocates into the plasma membrane after stress and is released into the extracellular environment in a membrane-associated form that activates macrophages. J Immunol 2008, 180:4299-4307.

52. Asea A: Release of Heat Shock Proteins: Passive Versus Active Release Mechanisms. In Heat shock proteins: potent mediators of inflammation and immunity. Edited by Alexzander A, Asea A, Antonio De M. Dordrecht: Springer Press; 2007:3-20

53. Asea A: Mechanisms of HSP72 release. J Biosci 2007, 32:579-584.

\section{doi:10.1186/1477-5956-11-24}

Cite this article as: Tian et al: Azacytidine induces necrosis of multiple myeloma cells through oxidative stress. Proteome Science 2013 11:24.

\section{Submit your next manuscript to BioMed Central and take full advantage of:}

- Convenient online submission

- Thorough peer review

- No space constraints or color figure charges

- Immediate publication on acceptance

- Inclusion in PubMed, CAS, Scopus and Google Scholar

- Research which is freely available for redistribution 